https://doi.org/10.48009/2_iis_2008_509-517

\title{
GROWING COMPUTER ADOPTION SUPPORTS INFORMATION SYSTEMS IN NONTRADITIONAL SETTINGS
}

\author{
Jean S. Adams, jeanadams@surfmk.com
}

\begin{abstract}
Traditional organizations, those with computer based information systems, have seen benefits from the continued adoption and integration of information systems into their business processes. There are still gaps in the research when looking at smaller nontraditional organizations usage of automated information systems. One reason for these gaps is the unique and individual needs of these organizations which make them difficult to study in mass. This paper compares the results of a 2007 study of information systems on Pennsylvania small farms to previous research conducted on the computer based information systems of large farms. The end result will begin to establish trends of adoption of computer based information systems in a nontraditional setting.
\end{abstract}

Keywords: Information systems, Computer adoption, Nontraditional organizations, Farm information systems, Small business systems, and Information management.

\section{INTRODUCTION}

New technology, real time data, and portability are the flagships of information management for many large corporations. Information systems powered by new technology coupled with the introduction of the Internet have been shown to support and improve decision making in large organizations. Organizations with automated information systems have harnessed the increased support into profitable returns.

Traditional organizations, defined as having established computer-based, (automated), information systems, have been the target of previous research spouting the success of automation and information management. The use of information systems is not limited by organizational size but less research has been conducted on smaller organizations to determine if computer usage supports organizational goals in the same manner. Research has even tackled small businesses, both in the manufacturing and service industries. These studies noted that many factors contribute to the manner in which smaller organizations utilize information management activities. But little research has looked outside of the traditional business setting to those nontraditional organizations to see if a similar level of advancement has been noted.

The aim of this paper is review computer usage and establishment of information systems in a nontraditional setting. This review begins to build and establish research in nontraditional settings. The nontraditional setting chosen for this review is that of small farm management. By benchmarking this nontraditional setting we can then compare and contrast the results to other research obtained in more traditional/larger settings

Determining the status of computer usage and information system trends in this particular setting will serve as an indicator for developing academic programs, planning extension programs, and also developing commercial software applications.

\section{BACKGROUND}

Information and the handling of information have become as important to organizations as the products they produce. Information has become a commodity for many organizations. The demand to manage both the inflow and the outflow of information challenges organizations from the day-to-day operational processes all the way through the strategic planning process. Organizations respond to this challenge by purchasing or developing tools that enable them to harness the power of information. Many authors define information systems as a primary tool enabling organizations to capture and manage information.

Identifying and studying information systems have been popular topics in research even more so with the introduction of the computer. Previous researchers have targeted traditional organizations when searching out the benefits of computers and information systems. Traditional organizations are defined as having established computer-based information systems. These organizations tend to be larger in size and have access to both capital and IT expertise enabling them to purchase, build, and maintain automated 
systems. Traditional organizations are found to implement standardized approaches to information management. This makes identifying and classifying the uses of information systems an academic exercise even between different industries.

Nontraditional organizations tend to be smaller in size and depend less on automated needs. Smaller organizations focus on satisfying operational needs before looking at other requirements. Each organization has individual and unique information requirements. Unique and individual assessments of information needs are primarily based on the labor skills available to smaller organizations. Smaller organizations have less access to the diverse IT and information handling expertise of larger organizations and must rely on the limited abilities to achieve goals. In other words they lack access to expertise for systems development and lack the manpower and capital of that available to larger organizations. Their approach to information management is less standardized and can be ad hoc at times. This makes their approach less standardized when compared to larger organizations and makes them more difficult to study in mass.

\section{SMALL FARMS}

Across the United States, today's farm operators face continuing challenges from global competition, urban sprawl, and scarce resources. New technology, government regulations, agriterrorism, and biological threats have required farm operators to gather and process data at an ever-increasing rate.

Today's farm operators must become information managers to survive and thrive. Case and Rogers [3] report that “today's agriculture exists in the context of an information society, and so the gathering, processing, and outputting of information is one of the most important roles of the modern farmer" [3].

One path to understanding how small farms (those with average yearly agricultural income of less than $\$ 100,000$ ) are addressing these information demands is to identify the types of information systems in use along with the levels of information automation that are occurring on small farms. Through the efforts of previous researchers of traditional organizations several models have been developed to identify and analyze information systems. These models do not address the uniqueness of smaller organizations or nontraditional organizations and must be adapted for this setting.

\section{LITERATURE REVIEW}

As with other research on information systems identifying farm information systems (FISs) is not a new topic in agricultural or academic research. Here again researchers have focused on large farm organizations applying standardized models that identify information systems. Large farms operate in a similar manner as other traditional corporate organizations. Much of the previous literature has focused on large farms, (those with gross receipts, i.e., sales and government payments greater than $\$ 100,000$ per year). Batte's [2]1995 study of large farms was one of the first studies to identify information systems by large farm operators. In his study Batte chose to use identification of computer based information systems as the model to classify the types of systems in place. Batte was able to use this approach due to the similarities that large farms have with traditional organizations with formal computer based information systems.

Previous literature has gone so far as to indicate that computer adoption on large farms assumes or can be equated to usage of information systems. Doye et al. [4] agree that computer adoption is a key indicator of information system adoption on large farms. They also found that the characteristics (factors) of farm operations that use a computer and those that have adopted a FIS were very similar. This provided the support needed to identify FISs on large farms using the models established by research conducted on traditional organizations.

But small farms like small businesses pose several other challenges when trying to identify information systems. El Louadi confirms in his study of small organizations [small businesses] that research needs to focus on the individuality of [small] organizations and not on applying standards developed in a different [larger] setting. This would aid the researcher to better understand how small organizations operate [5]. Hunter confirmed in his 2004 study of small businesses that "small businesses [organizations] tend to emphasize the use of information systems for more immediate daily operations" [7]. Hunter also documents that small businesses [organi- 
zations] are "limited to what activities can be initiated with the scarce resources and talents" available to them [7]. Therefore, by restricting research objectives to only those standards adopted by larger traditional computer based organizations, the researcher will not achieve the intended results.

S. Harsh writes that "it appears that the difficult decisions currently facing managers of farms businesses are increasingly semi- or unstructured in nature and strategic in scope, whereas that the problems of a few years earlier were more structured in nature and operational in scope. This suggests that the transition from the 'old economy' to the 'new [information] economy'” [6]. This transition to an information age added to the uniqueness of the small farm operator provided a challenge to overcome before data can be gathered for research.

\section{MODEL DEVELOPEMENT}

The first task of this 2007 study was to develop a model that could account for the uniqueness of the small farm setting while maintaining the previously established definition of information systems; a tool that makes information usable to the end user. The approach applied by this study was to develop a model that blended both the key fundamentals of information management and the core requirements of farm management. In their book Essentials of MIS, Laudon and Laudon [10] define an information system as "a set of interrelated components that collect (or retrieve), process, store, and distribute information to support decision making, coordination, and control in an organization. In addition to supporting decision making, coordination, and control, information systems may also help managers and workers analyze problems, visualize complex subjects, and create new products” [10].

Applying these definitions to this study of small farms, farm information can then be defined as any type of information used to perform farm activities or information that is used to deal with a farm problem. The definition of a farm information system can then be extended as a tool to "assist farms in forward planning, risk management, and the control function of farm management” through the use of information [4].

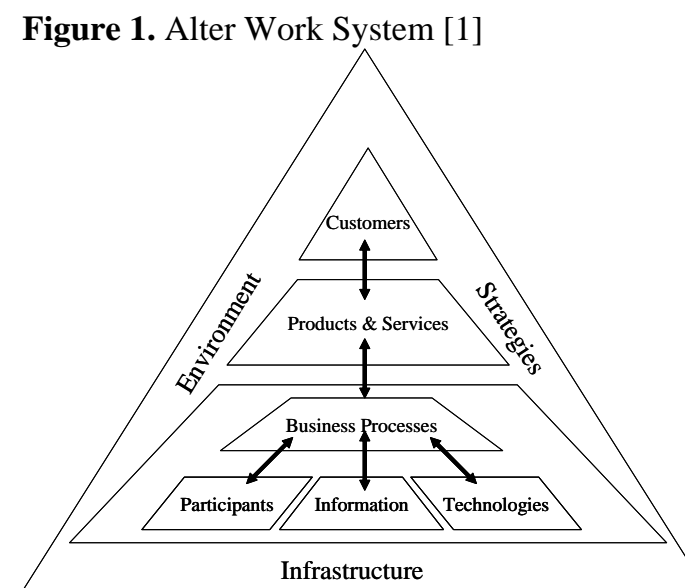

Our model must first be able to identify the mechanics necessary to gather, process, store, and distribute information and second identify if the information gathered is processed to support management of the organizations. This twopronged approach was achieved by blending two models previously developed in information system research. Alter's framework of work systems (See Figure 1) was the cornerstone for identification of information processes. According to Alter, a "work system is a system in which human participants and/or machines perform business processes using information, technologies, and other resources to produce products and/or services for internal or external customers"[1]. Alter defines an "information system as a special case of a work system in which the business processes preformed and products and services produced are devoted to information” [1]. Alter's work system is not limited to computerbased organizations and is also not constrained by an organizations size. This makes application to this nontraditional setting ideal. Alter's model is constructed to analyze the activities that an organization undertakes to achieve a desired organizational outcome such as producing a product. It is not product specific and requires only understanding the information stream of an organization.

The second requirement of our model is that the information generated from an information system be used to support the management of the organization. Due to the uniqueness found in nontraditional organizations Alter's model alone does not meet the requirements of identifying 
information systems in nontraditional settings. We again return to previous research and established models to search out a management model specific to the industry and environment to be studied.

Kay’s [9] functions of farm management, planning, implementation, and control offers a structured approach for organizing information that enables farm operators to reach their agricultural goals. Kay [8] defines farm management to be "the decision making process whereby limited resources are allocated to a number of production alternatives to organize and operate the [farm] business in such a way as to attain some objectives" This requires that informed decision making occur in all three basic management functions: planning, implementation, and control. Without adequate planning, implementation, and control, valuable time and resources may be wasted or even destroyed which in a farm setting is detrimental.

Kay's functions of farm management provide a filtering process to disseminate and classify the many different information inputs that are used for farm management. These functions of farm management not only classify what information is critical to farm managers but also serve as a guide for gathering data related to farm management activities. Kay's functions of farm management can be expressed as a cycle where information is used to navigate and move through each of the stages: planning, implementation, and control. This cycle is illustrated in Figure 2.

Together Alter's works systems and Kay's farm management functions address the unique information needs of farm managers. The resulting model provides the roadmap needed to conduct research in this nontraditional setting.
Figure 2. Kay’s Functions of Farm Management [8]

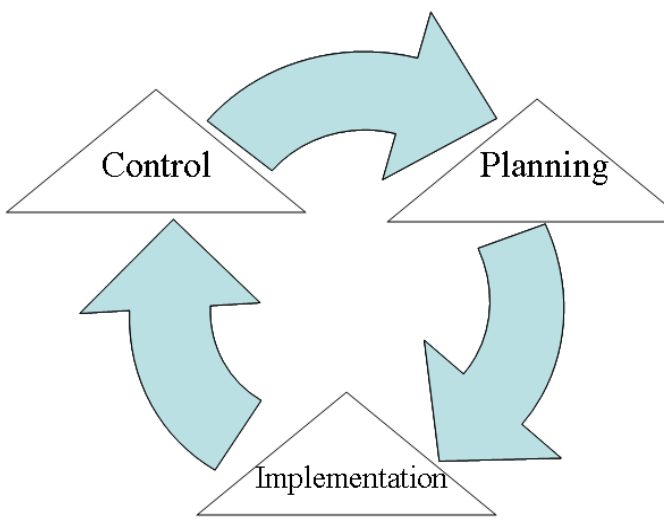

\section{STUDY OVERVIEW}

The resulting tow-pronged model (Figure 3) was introduced in a 2007 quantitative study conducted with small farm operators located in Pennsylvania. One research objective of the study was to identify if information systems existed on small farms and if so to categorize the types of systems in place. Data was also gathered to determine if systems were manual or computer based.

\section{Methodology}

The sample was drawn from the population of agricultural operators in Pennsylvania. According to the National Agriculture Statistics Service [11] the target population consists of over 48,000 farm operators who reside in Pennsylvania and whose average yearly agricultural income is less than \$100,000 per year. The Pennsylvania Associations for Sustainable Agriculture (PASA) and the Pennsylvania Women's Agricultural Network (WAGN) two agricultural based organizations worked with the researcher to identify and contact potential participants. A second source of participants came from visits to agricultural fairs held throughout Western Pennsylvania. Through these methods 100 usable data sets were collected. The researcher noted the convenience of this sample but also recognized that due to the exploratory nature of this study the convenience and size of the sample did not impact the primary research objectives.

The first step of the model application was to identify the work systems of the small farm operator. Questions were developed to meet the 
model requirements identified in Figure 3 . Questions were aimed at the identification of the components of a work system: processes/routines participants, information needs, technologies, environment, strategy, and infrastructure. Close-ended multiple-choice questions were used to gather data on each component. To ensure adherence to the established approach survey questions were assigned and mapped to each model component. This safeguarded against favoring one component over another and that all components were considered in the final outcome of this study.

Figure 3. Farm Management Functions Applied to the Work System Method

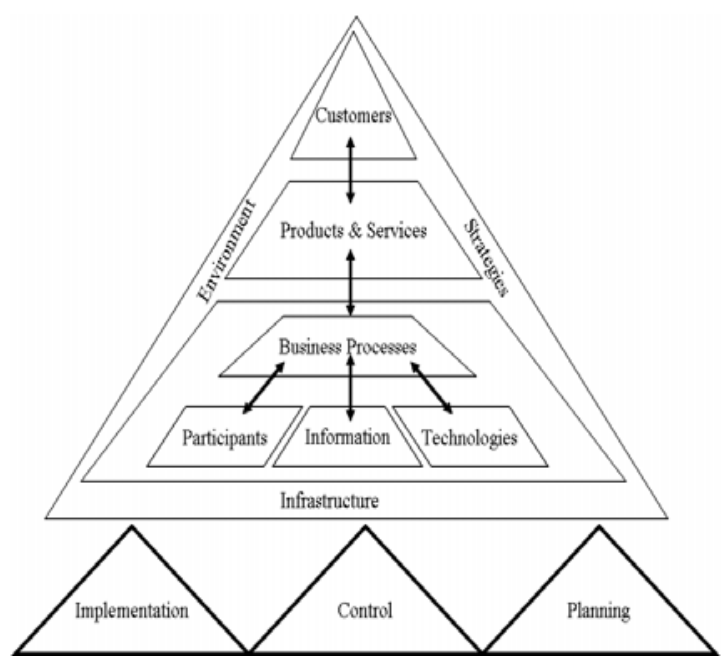

Participants were asked to indicate the type of information for which they maintain records. Livestock breeding schedules, pesticide applications, and cash-flow information are only a sample of the areas that participants were asked to review. Once information records were identified participants reported on the processes, methods, or procedures used to gather each type/record of information. Examples of processes included but were not limited to the following: a notebook, markings on a barn wall, computer based tracking system, calendar, or none at all. Participants were also asked if the information they collected was processed or analyzed in any other fashion. And finally if the information was stored in the same format that it was gathered or was a secondary process introduced before storage. Participants were also asked to identify if information from prior years, in whatever format, was ever consulted to aid current decision-making processes.
The above questions established the work systems involved. The second step of the model application was to determine if the work systems identified in step one supported farm management functions as identified by Kay. Survey questions were developed to determine the environment, infrastructure, and strategies present on each farm. By studying the interaction of the three elements environment, strategies, and infrastructure we can determine "if a work system can operate as intended and can accomplish its goals” [1] thereby producing a decision support system. The interactions of these three elements of farm management provide the ability to apply Alter's model to small farms.

\section{Results}

One hundred usable data sets were received from participants responding to the questionnaire. Participants identified financial records, crop records, and livestock records as the three areas in which information is gathered, processed, and maintained. Through the use of the model identified in Figure 3 it was determined that although each farm had similar agricultural goals the implementation of their data collection processes and the data that each gathered was unique and not similar. This was not unexpected and followed patterns established by research conducted on small businesses. For purposes of this research it was not necessary to establish a standard only to establish that data was gathered through some identifiable process. Participants also described the physical process or methods used to gather and maintain their records. The approach established in this study proved successful in determining the existence of FISs in the areas of financial management, crop management, and livestock management. This approach also helped to identify automation levels in each system.

\section{BENCHMARKING FIS AND AUTOMATION}

As the literature has shown little has been done to update the status of FIS usage on large farms and even less focus has been placed on small farms. Although several developments should have been shown to accelerate the adoption and use of automated information systems, (in both traditional and non traditional settings), including low cost, reliable, and portable hardware systems, networking technology, analytical skills, knowledge of decision makers and better soft- 
ware design [6]. There has not been significant research on small farms to identify if they are benefiting from these developments. In order to benchmark information systems usage on small farms we will compare our recent 2007 study results with those of several studies conducted on farm information management starting as early as 1995.

The Batte [2] study of 1995 focused on large farms (those with over $\$ 100,000$ gross sales). Participants represented 13 Mid Western states and averaged over $\$ 200,000$ of gross sales with $8 \%$ having greater than $\$ 500,000$. This study was one of the foundation studies conducted in FIS applications and focused on computer adoption as the primary indicator of information system adoption. Successful Farming a journal dedicated to farm enrichment also conducted a study in 1995 that focused on computer usage at the farm level. The 1995 Batte study was repeated by Doye et.al. in 2000 [4] using a qualitative approach and reviewed information system usage and the factors contributing to FIS usage along

Table 1. Computer Adoption

\begin{tabular}{lc}
\hline \multicolumn{1}{c}{ Study Description } & $\begin{array}{c}\text { Recorded } \\
\text { Computer } \\
\text { Adoption }\end{array}$ \\
\hline Batte 1995 & $26.7 \%$ \\
NASS 1997 Pennsylvania & $14.0 \%$ \\
NASS 2003 Pennsylvania & $48.0 \%$ \\
FIS on Small Farms 2007 & $77.5 \%$
\end{tabular}

with automation.

The United States Department of Agriculture's National Agricultural Statistics Services [11] (NASS) also recognized the importance of computer adoption and began gathering data on computer usage by farm operators beginning in 1997. They too have recognized that farm operations exist in the new information age and are looking to identify trends in this area. Every two years the NASS conducts a farm census gathering data from large and small farms across the United States. These primary sources of data will be compared and contrasted to review the trend of computer adoption on small farms.

Although the populations of these surveys are not comparable on a systems level they are comparable for benchmarking and trend analysis. This is primarily due to the fact that all partici- pants have access to or could be influenced by the factors that support increased computer adoption: including low cost, reliable, and portable hardware systems, networking technology, analytical skills, knowledge of decision makers and better software design. These previous studies provide datasets that are useable for trend analysis. The focus of this paper is to begin to benchmark and identify if small farms are seeing the same growth in computer based information system usage other documented populations have seen. This comparison should provide insight and possible direction for future works.

\section{FIS DOCUMENTED THROUGH COMPUTER OWNERSHIP}

Even as early as the 1995 Batte [2] study adoption of information systems was tied to computer adoption/ownership. Table 1 shows the computer adoption rate of farm operators from 1995 through 2007 as reported in the previously mentioned studies. Table 1 shows the percentage of participants in each study in which a computer was in operation at the farm site. The data does not specify for what type of activities computers are being used or even if any of the activity is associated with farm management. As identified in Table 1 computer adoption on farms has grown from $26.7 \%$ to $77.5 \%$ of the population having on site computer access. It does not indicate that farm management activities are occurring on a computer but does show that computer usage on small farms is trending in the same direction as other populations.

The large step increase between the NASS 2003 data of $48.0 \%$ to the results of this $2007,77.5 \%$, study maybe contributed to the methodology used to contact participants in the 2007 study. Members of PASA and WAGN belong to an email network and were contacted via email. Obviously a computer must be involved if you are participating electronically. This is brought to the attention of the reader for clarification and even though it may have contributed to the significant increase it does not take away from a positive trend. The introduction of the Internet has been previously listed as a contributor to increased computer adoption and the existence of email networks documents the relationship between these factors. 


\section{INVENTORY OF FIS}

\section{Types of FIS}

The primary goal of the 2007 study was to identify the existence of farm information systems and then to classify the types of systems being used. This again was accomplished through the model established in Figure 3. Through closed ended questions participants identified financial, crop, and livestock management as the three areas in which information is gathered and maintained. Each farm gathered unique data in each area critical to their own needs and goals. Here again the model in Figure 3 is not concerned with the type or uniqueness of information but only that information is gathered, processed, and maintained to fulfill the core components of an information system. For this paper the data recorded in the 2007 study was filtered to review only those farms in which a computer was used to process records. Table 2 represents a comparison of the results of the Adam's 2007 study compared to the other previous studies looking only at instances when a computer is used for business planning, tax preparation, livestock production records, and crop production records.

As identified in Table 2 there is significant growth in the livestock production records area moving from $29.9 \%$ to $70.2 \%$. This may be attributed to current health concerns and new regulations that require frequent updates of livestock information. It may also be due to increased availability of software applications targeted at livestock production. Livestock tracking is an easily adapted database application. It is also not surprising that crop records dropped by almost 50\%. The Batte 1995 study [2] was conducted on large farms that produce much of the commercial food source for the United States. The production rates on the small farms participating in the 2007 study may not require the same diligence as these larger farms. Another reason that may contribute to this difference is that a large portion of the participants were family owned farms and as such crop yields may be used for family consumption only. Interestingly $50.6 \%$ of the 2007 study did track fertilizer usage manual methods not invoking a computer. When combined this ratio of records makes the small farm group equivalent to the earlier studies on large farms although they did use less automated process.

Table 2 also documents that tax preparation, financial planning and accounting remain three areas where computer usage is most highly adopted in all three studies. The 2007 study shows a slight decrease in computer usage as compared to the other studies but this may also be contributed to the organizations structures. In the earlier studies most organizations were corporations as compared to the predominantly family owned business in the 2007 study. Corporations are required to maintain and track a large number of financial submittals and a computer would be very helpful in this area. Established software packages are dedicated to financial record keeping for larger settings again making it more accessible to these organizations. Even though the usage level is lower it still shows a positive trend that computer usage is growing on small farm. The predominant use of automated FIS systems to support small farm management was as follows: Financial systems were used to identify unprofitable business sectors and monitor cash flow. Crop systems were used to track and review fertilizer soil analysis. Livestock systems were used for birthing/breeding planning and feed application. This usage trend is similar to what was seen in the earlier studies and continues to support the thesis that small farm organizations are experiencing similar benefits as those recognized by larger farms when discussing computer usage.

\section{Method of Collection}

Financial records were tracked both manually and through the use of a computer. Crop records were tracked in the same manner with some participants reporting using just a simple notebook system or markings on a calendar. Livestock

Table 2. Usage of Farm Level Computers

\begin{tabular}{lccc}
\hline & Batte 1995 & $\begin{array}{c}\text { Successful } \\
\text { Farming Sur- } \\
\text { vey 1995 }\end{array}$ & $\begin{array}{c}\text { FIS on Small Farms } \\
\text { in Pennsylvania 2007 }\end{array}$ \\
\hline Business Financial Accounting & $86.2 \%$ & $86.0 \%$ & $76.0 \%$ \\
Business Analysis Planning, Tax Preparation & $72.2 \%$ & $67.9 \%$ & $65.0 \%$ \\
Livestock Production Records & $29.9 \%$ & $27.5 \%$ & $70.2 \%$ \\
Crop Production Records & $52.2 \%$ & $39.0 \%$ & $27.3 \%$
\end{tabular}


records were also gathered using similar methods and several participants also listed tracking markings only a barn wall or fence post. All of these methods meet the requirements of an information system for our study due to the fact that the results are used for decision-making.

Table 3. Collection Method - Computer Aided

\begin{tabular}{lcc}
\hline \multicolumn{1}{c}{ Information Type } & $\begin{array}{c}\text { Batte } \\
1995\end{array}$ & $\begin{array}{c}\text { FIS on Small } \\
\text { Farms in } \\
\text { Pennsylvania } \\
2007\end{array}$ \\
\hline $\begin{array}{l}\text { Business Financial } \\
\text { Accounting }\end{array}$ & $29.5 \%$ & $59.0 \%$ \\
$\begin{array}{l}\text { Livestock Produc- } \\
\text { tion Records }\end{array}$ & $10.1 \%$ & $32.2 \%$ \\
$\begin{array}{l}\text { Crop Production } \\
\text { Records }\end{array}$ & $14.3 \%$ & $36.4 \%$
\end{tabular}

Table 3 depicts only the records that were gathered through the use of a computer. As the results in Table 3 show significant growth has been documented for computer usage as a method to gather information even in the non traditional setting of small farms. In all three areas, financial, livestock, and crop records computer usage as a collection tools has more than doubled from the original studies. The difference between Table 2 and Table 3 is that Table 3 looks only at the record collection methods whereas; Table 2 looks at the processing of data and information. As stated earlier small organizations fulfill their operational needs first before other needs. Gathering information on a computer to be analyzed manually fits this pattern. Fewer software packages, lack of knowledge about applications, and use of external experts are only a few reasons why the computer may only be a data collection tool.

\section{CONCLUSIONS}

Combining two established and accepted information models used in research of traditional organizations provides an exploratory tool for identifying information systems in the nontraditional setting of small farms. This approach could easily be used in other nontraditional settings and provides a stepping-stone to understanding the uniqueness of these environments. It also begins to show the depths that technology primarily the computer is having on our environment.
The result of this 2007 study, when compared to previous studies, does show that computer usage is growing even on the small farm. It also indicates that the patterns of growth are mimicking the same patterns seen in the growth of automated information systems of large farms just a decade ago.

I acknowledge that the participants were a convenient sample and the numbers of responses, although small, was sufficient for this type of exploratory study. A more robust sample would be needed to draw more specific conclusions. Future research will include a larger sample and could also include large farms to provide a one to one comparison. Future research could also look at other nontraditional settings for even further comparisons. The scope for this article was only to identify the levels of computer based information systems on small farms. The rate of technology change and ever increasing information requirements can only drive the usage of information systems upward.

\section{REFERENCES}

1. Alter, S. (2002). The work system method for understanding information systems and information system research. Communications of the Association for Information Systems, 9, 90-104.

2. Batte, M. (Ed.). (1995). Adoption and use of farm information systems- OARDC Special Circular 149. Ohio: The Ohio State University.

3. Case, D. \& Rogers, E.(1987). The adoption and social impacts of information technology in U.S. agriculture. The Information Society, 5, 57-66.

4. Doye, D, Jolly, R., Hornbaker, R., Cross, T., King, R., Lazarus, W., Yeboah, A., Rister, E. (2000, August) Farm Information Systems - Their Development and Use in Decision Making. Extension Distribution Center.

5. El Louadi, M. (1998) The relationship among organizational structure, information technology and information processing in small Canadian firms. Canadian Journal of Administrative Sciences, 15(2), 180-199. 
6. Harsh, S. (1998) Agricultural Information Systems: Current Applications and Future Prospects, The Asian Federation for Information Technology in Agriculture, 1-7.

7. Hunter, M.G. (2004). Information Systems \& Small Business: Research Issues. Journal of Global Information Management, OctDec , 12,4, i-iv.

8. Kay, R.D., (1986). Farm Management: planning control and implementation, 2nd ed., McGraw-Hill, New York.

9. Kay, R.D. and Edwards, W. M. (1999). Farm Management, 4th ed. McGraw-Hill, Boston.

10. Laudon, J.C. and Laudon, J.P. (2002) Management Information Systems: Managing the Digital Firm, 7th ed. Prentice-Hall, Englewood Cliffs, NJ.

11. NASS (2004). Pennsylvania Agricultural Statistics 2003-2004, National Agricultural Statistics Service, Pennsylvania Statistical Office. 